\title{
Intersetorialidade, determinantes socioambientais e promoção da saúde
}

\author{
Intersectoriality, social and environmental determinants \\ and health promotion
}

\author{
Kênia Lara Silva ${ }^{1}$ \\ Roseni Rosângela Sena ${ }^{2}$ \\ Marco Akerman ${ }^{3}$ \\ Stephanie Marques Moura Belga ${ }^{1}$ \\ Andreza Trevenzoli Rodrigues ${ }^{1}$
}

${ }^{1}$ Departamento de Enfermagem Aplicada, Escola de Enfermagem, Universidade Federal de Minas Gerais (UFMG). Av. Alfredo Balena 190, Centro. 30130-100 Belo Horizonte MG Brasil.

kenialara17@gmail.com

${ }^{2}$ Departamento de

Enfermagem Maternoinfantil e Saúde Pública,

Escola de Enfermagem,

UFMG.

${ }^{3}$ Departamento de Prática de Saúde Pública, Faculdade de Saúde Pública, Universidade de São Paulo.

\begin{abstract}
The study seeks to analyze intersectoriality from the socio-environmental perspective on health promotion. Qualitative research was conducted in six municipalities in Belo Horizonte, Minas Gerais, Brazil. The data were obtained from the mapping of health promotion experiences considered successful by municipal managers, interviews with coordinators, professionals and participants and observations of participants of the practices. The data were subjected to thematic content analysis. Intersectoriality was revealed as a premise for the political definition of the majority of the practices. At the normative program level, the social assistance sector has shown greater potential to develop intersectorial practices and centrality in the implementation grid due to its involvement with the social and environmental determinants. The results indicate that there is a gap between the intention to practice intersectoriality, witnessed by the political decisions in the municipalities, and effective intersectorial action in everyday life. The conclusion reached is that there is potential for intersectorial interventions on the social and environmental determinants in favor of health promotion, but the lack of consistency between what occurs in practice and the political aspects reveal a challenge to be overcome. Key words Health promotion, Intersectorial action, Social determinants
\end{abstract}

Resumo O presente estudo objetiva analisar a intersetorialidade na perspectiva socioambiental de promoção da saúde. Pesquisa qualitativa realizado em seis municípios da região metropolitana de Belo Horizonte, Minas Gerais, Brasil. Os dados foram obtidos do mapeamento de experiências de promoção da saúde consideradas exitosas por gestores municipais; entrevistas com coordenadores, profissionais e participantes das práticas; observações participantes das práticas. Os dados foram submetidos à análise de conteúdo temática. A intersetorialidade foi revelada como premissa na definição política da maior parte das práticas. No plano programático normativo, o setor de assistência social demostrou maior potencial para desenvolver práticas intersetoriais e centralidade na rede de articulação face à sua implicação com os determinantes socioambientais. Existe um distanciamento entre a intenção de praticar a intersetorialidade, evidenciada nas determinações políticas dos municípios, e a sua efetivação no cotidiano. Conclui-se que há potencialidade para intervenções intersetoriais sobre os determinantes socioambientais a favor da promoção da saúde, mas a inconsistência entre o operacional praticado e os aspectos políticos explicitam um desafio a ser superado.

Palavras-chave Promoção da saúde, Ação intersetorial, Determinantes sociais 


\section{Introdução}

O conceito de promoção da saúde tem sido construído ao longo da história e um dos marcos se constitui na realização das Conferências Internacionais de Promoção da Saúde, ressaltando o protagonismo dos determinantes sociais sobre as condições de saúde ${ }^{1,2}$. Entre as diferentes abordagens admitidas ao tema emergiu a concepção socioambiental sobre promoção da saúde, que inclui em seu campo conceitual e prático as condições propiciadas pelos aspectos físicos, sociais, econômicos e culturais nos quais indivíduos e coletivos estão inseridos, indicando a amplitude e a complexidade das ações ${ }^{3,4}$.

A abordagem socioambiental fundamentase no potencial de saúde para impulsionar uma vida que vale a pena ser vivida, cujo foco direciona-se ao atendimento das necessidades de saúde dos sujeitos. Adota como principais estratégias as ações políticas, a promoção de espaços saudáveis, o empoderamento dos sujeitos, o desenvolvimento de habilidades, conhecimentos e atitudes favoráveis à saúde. Os programas sustentados por essa abordagem são constituídos por constante diálogo crítico reflexivo entre a comunidade, os profissionais e as agências governamentais e não governamentais $^{1,3}$.

Ante a complexidade do ideário socioambiental de promoção da saúde visualizam-se limites nas intervenções setoriais, isoladas e fragmentadas. Por conseguinte, há a necessidade do desenvolvimento de estratégias intersetoriais, operacionalizadas por meio de ações coordenadas entre os diferentes setores sociais, ações do Estado, da sociedade civil, do sistema de saúde, dentre outras ${ }^{5}$, para a promoção da saúde de indivíduos e comunidades.

Para essa discussão, contamos com a contribuição de Potvin ${ }^{6}$ ao afirmar que vários modelos explicativos reconhecem que saúde é produzida na vida diária e, portanto, extrapolando a atuação exclusiva do setor saúde. Tomou-se como cenário o território dos municípios por entender que neste espaço acontece o cotidiano das pessoas, tendo o potencial para se exercitar a intersetorialidade.

A articulação de saberes e experiências para a solução sinérgica de problemas complexos é um conceito citado por autores para dar significado à intersetorialidade ${ }^{7,8}$. Inojosa ${ }^{9}$ discute as implicações do termo "sinergismo" contido no conceito de intersetorialidade e afirma que a proximidade de saberes isolados, sem gerar novas articulações ou prosperidade de diálogo, não é capaz de pro- mover soluções sinérgicas e, portanto, não concretizam a intersetorialidade.

Assim, esta não se limita à justaposição de projetos que são formulados e realizados setorialmente, mas compreende um processo de planejamento participativo que inclui as fases de análise de situação, escolhas estratégicas e operacionalização ${ }^{9,10}$. Neste processo, ressalta-se a relevância da integração com a comunidade para o levantamento crítico de suas necessidades e interpretação dialética da realidade . $^{8}$.

As intervenções isoladas possuem baixa efetividade para promover qualidade de vida, fomentar desenvolvimento e superar a exclusão social. A consistência das práticas intersetoriais diz respeito à concretude de programas bem estruturados com objetivos, planejamento e gestão compartilhados, bem como orçamentos próprios ${ }^{10}$.

Contudo, a vivência dos pesquisadores em estudos no campo da promoção da saúde tem revelado que existe uma ampla documentação sobre a necessidade de trabalho intersetorial, mas há uma deficiência de investigações sobre a implantação, sustentabilidade e avaliação de práticas intersetoriais em saúde ${ }^{11}$. A escassez de estudos em profundidade sobre as ações intersetoriais existentes é apontada como desafios para o crescimento e aprimoramento da intersetorialidade $e^{6,12}$, o que torna pertinente a presente discussão sobre aspectos conceituais e operacionais dos mecanismos intersetoriais instituídos em práticas de promoção da saúde em seis municípios de grande e médio porte.

Assim, o objetivo deste estudo é analisar a intersetorialidade na perspectiva socioambiental de promoção da saúde, revelando seus aspectos conceituais e práticos em programas e ações desenvolvidas pelos setores Saúde, Educação, Assistência Social, Cultura e Esporte e Lazer, em seis municípios.

\section{Metodologia}

O estudo teve suporte na abordagem qualitativa tendo como referencial a dialética. A dialética marxista abarca não somente o sistema de relações que constrói o modo de conhecimento exterior ao sujeito, mas também as representações sociais, que constituem a vivência das relações objetivas pelos atores envolvidos, que lhe atribuem significados ${ }^{13}$.

O percurso metodológico do estudo compreendeu três fases: mapeamento das experiências de promoção da saúde nos municípios cenários; 
análise em profundidade das práticas, experiências de promoção da saúde; construção de uma matriz analítica.

Foi realizado um mapeamento das experiências de promoção da saúde nas áreas de saúde, educação, cultura, assistência social e esporte-lazer de seis municípios da Região Metropolitana de Belo Horizonte (RMBH), Minas Gerais, Brasil. Foram incluídos municípios representantes de diferentes faixas populacionais desde aqueles com menos de 10.000 habitantes a outros com população acima de 500.000 habitantes. O mapeamento partiu de entrevistas com gestores das áreas de estudo que indicaram 29 práticas exitosas para a promoção da saúde. Considerou-se como exitosas aquelas práticas que os gestores identificassem, no âmbito de sua gestão ou de setores afins, que impactassem positivamente na qualidade de vida da população.

A análise em profundidade das práticas/experiências de promoção da saúde foi realizada a partir de observações participantes periféricas, momento no qual também ocorreram entrevistas com coordenadores, profissionais e participantes das práticas.

A observação participante periférica é um procedimento de coleta sistematizada de dados que permite identificar as atividades nas quais as pessoas estão inseridas no contexto da ação ${ }^{14}$. Assim, a presença dos pesquisadores nas cenas concretas permitiu captar valores, conceitos e tecnologias que não necessariamente seriam captados em entrevista (quando geralmente se fala do "dever ser"). O número de observações de uma mesma prática foi definido a partir da avaliação do pesquisador, após julgar concluído o objetivo da observação, e os dados foram registrados em diário de campo para compor o corpus empírico do estudo.

Os dados provenientes das entrevistas foram submetidos à análise de conteúdo temática e os registros em diário de campo foram utilizados de forma complementar para aprofundar a compreensão do objeto estudado.

Nos Municípios 1 e 2, com contingente populacional acima de 500.000 habitantes, foram analisadas, respectivamente, sete práticas (três do setor saúde, duas do setor educação e duas do setor assistência social) e dez práticas (uma do setor saúde, uma do setor educação, duas do setor esporte e lazer e seis do setor assistência social).

No Município 3, com população aproximada de 500.000 habitantes, foram analisadas duas práticas, sendo ambas do setor saúde. No Município 4, com população aproximada de 100.000 habitantes, foram analisadas seis práticas, sendo uma do setor saúde, uma do setor educação, uma do setor cultura, duas do setor esporte-lazer e um do setor assistência social. Nos Municípios 5 e 6, com contingente populacional abaixo de 10.000 habitantes foram analisadas, respectivamente, uma prática (setor educação) e três práticas (uma do setor educação, uma do setor cultura e uma do setor assistência social).

$\mathrm{Na}$ apresentação dos resultados, foram utilizados códigos para representar as práticas, compostos pela letra $\mathrm{P}$ (Prática de promoção da saúde) ordenada de 1 a 29; seguido das iniciais do setor de vinculação $(\mathrm{S}=$ Saúde, $\mathrm{E}=$ Educação, $\mathrm{C}=$ Cultura, A = Assistência Social, L = Esporte e Lazer) e classificadas pelos municípios de M1 a M6.

A construção da matriz analítica foi realizada com os elementos identificados nos discursos e aqueles advindos da observação das práticas. A análise foi orientada pelas categorias; definição política, plano programático-normativo e aspectos operacionais, que caracterizam a intersetorialidade nas práticas analisadas nos municípios. Procurou-se demonstrar as coerências e as contradições referentes aos aspectos ideológicos e práticos da intersetorialidade como premissa da abordagem socioambiental da promoção da saúde.

$\mathrm{O}$ estudo respeitou todos os aspectos éticos da pesquisa envolvendo seres humanos, tendo sido aprovada pelo Comitê de Ética em Pesquisa da Universidade Federal de Minas Gerais. Os sujeitos foram informados sobre os objetivos e as finalidades do estudo e assinaram o Termo de Consentimento Livre e Esclarecido (TCLE).

\section{Resultados}

Os discursos dos gestores setoriais e coordenadores de práticas de promoção da saúde revelaram que há reconhecimento sobre a necessidade de ações intersetoriais para potencializar os resultados. Neste sentido, a intersetorialidade é entendida como uma estratégia para resolver problemas que extrapolam o âmbito de atuação setorial e é referida como uma política proposta para orientar e organizar a promoção da saúde nos municípios cenários.

[...] Porque as questões sociais, elas batem na porta da unidade básica de saúde. Então a resolução não ta ali, ta nessa ação intersetorial, ta fora da saúde, e saúde também. Melhoria das condições de vida, sociais, econômicas, educacionais, então está muito fora da [do setor] saúde (Gestor da Saúde do Município 1). 
Eu vejo que de repente deveria ser mais articulado mesmo, uma vez que o cliente é o mesmo (Gestor da Educação do Município 3).

Várias dessas coisas que você vê não foram feitas somente pela educação, mas tem uma decisão política e uma orientação para uma agenda intersetorial que no final das contas essa ação vai se desdobrar dentro da escola (Gestor da Educação Município 1).

Entre os setores estudados, a Assistência Social revelou ser um espaço potente para disparar articulações intersetoriais com ações que demandam outros setores e equipamentos sociais, em especial a Saúde e a Educação. Um dos gestores municipal entrevistado explicita que, apesar de a Assistência Social ser o setor que assume a intersetorialidade como prioridade, permanece o desafio de operacionalizar esse princípio:

Hoje é a secretaria que tem a finalidade, digamos de zelar, operar a intersetorialidade. A responsabilidade não é exclusiva. Todos os setores têm que ter essa concepção. Mas, quem não está no dia-adia às vezes não percebe como é complicado vocêfazer com que um agente comunitário de saúde tenha uma referência no CRAS, valorize o trabalho da assistente social ou o médico da família recomenda que o menino participe de uma oficina de esportes (Gestor Assistência Social Município 1).

Outros participantes do estudo também expressam que diversos programas e práticas planejados para serem desenvolvidos de forma intersetorial não alcançam o propósito, limitando-se ao estabelecimento de parcerias pontuais, de modo a evidenciar contradições entre o ideal planejado e o realizado na prática dos municípios.

A palavra intersetoriedade é muito falada, mas as ações intersetoriais ainda acontecem muito fragmentadas. Elas não têm uma ação mesmo efetiva, que seja efetivamente intersetorial. Elas são ações de diferentes secretarias. O objetivo desta política e realmente fazer com que estas ações sejam intersetoriais na sua efetividade (Gestor Saúde Município 2).

Na rede intersetorial, a relação EducaçãoSaúde revelou-se permeada de tensões tanto no que se refere ao planejamento das ações quanto à sua operacionalização. Apesar do interesse em estabelecer uma articulação intersetorial entre os dois setores, evidenciam-se parcerias pontuais e encaminhamentos de situações consideradas como problema.

Uma das nossas linhas é pensar que a criança no momento que a gente aferir a pressão arterial, se a gente detectar, por exemplo, que a criança está com uma hipertensão, o tratamento dela não tem que ser feito na escola, a gente tem é que referenciar a criança lá na equipe de saúde da família, ela tem que ser atendida, então não é trazer o hospital para dentro da escola, mas é ação intersetorial, usando os espaços e recursos que a educação tem e que a saúde tem, e potencializar esses recursos, porque aí um vai complementando o outro (Gestor Educação Município 2).

Principalmente o encaminhamento de alunos, a gente vai a visitas, vê se há necessidade de encaminhamento para saúde, a gente busca a saúde para estar atendendo esses alunos em determinadas situações. Ai é de acordo com a demanda (Gestor Educação Município 3)

Os resultados apontam a manutenção da fragmentação setorial nas estruturas das organizações, evidenciada por entraves que inviabilizam a operacionalização da intersetorialidade. Dentre os entraves mencionados destacam-se a ausência ou incipiência de espaços destinados ao diálogo entre setores, profissionais e sociedade.

Os resultados revelam que o setor cultura, no contexto dos municípios estudados, desenvolve algumas práticas que se ancoram nos princípios da promoção da saúde, ao valorizarem a concepção holística do processo saúde-doença, o senso de pertencimento e a cidadania. Apesar disso, a interlocução com outros setores foi revelada como insuficiente, como apreendido na análise de outros setores.

É muito complicado. Cada setor dessa tem seus seminários, suas conferencias anuais, às vezes até por exigência de alguns sistemas estaduais ou nacionais. Ai faz gestões separadas, fica cada um para um lado. Não faz uma coisa horizontal, não trama isso como um projeto para cidade que teria que ser obrigado a rezar numa cartilha num ritmo só, todo mundo (Gestor Cultura Município 6).

No contexto dos seis municípios constitutivos do cenário do estudo, três apresentaram avanços em relação à operacionalização da intersetorialidade por meio da articulação de diferentes setores em grupos de trabalho que se reúnem com o objetivo de discutir e planejar propostas de intervenção com vistas à promoção de saúde.

A gestão passada tinha uma visão muito deste grupo de trabalho com modos de vida saudáveis. Então as atividades estruturadas eram muito voltadas para a questão da alimentação saudável e da prática frequente de atividade física. A gente tentou ampliar um pouco mais, convidando outros atores, pensando na questão dos determinantes sociais de saúde (Gestor Saúde Municipio 1).

A gente tem um grupo de trabalho. É nessa perspectiva mesmo, de integração de todas as secretarias, 
em torno deste programa da educação integral. Então, agora a gente já está avançando nessa articulação com outras secretarias. Já estava bastante consolidada com a saúde e com o Desenvolvimento Social, mas, agora a gente já está avançando para uma integração com a secretaria de defesa social. [...] Então, a gente está vivendo um processo riquíssimo e muito desafiador (Gestor Educação Município 2).

Quinzenalmente ocorre a reunião de rede. Então, esse espaço é pra fazer discussão de alguns casos. Então, é para a gente ir alinhavando algumas coisas enquanto município mesmo. Assim, onde que essa rede ainda tem falha, que tipo de equipamento de serviço o município precisa de ofertar para que essa rede flua melhor? (Gestor Assistência Social Município 3)
Foi evidenciado que a organização dos espaços de articulação tem como motivação o esforço coletivo para resolver problemas sociais complexos, tais como, questões relacionadas à violência urbana e vulnerabilidade social.

A matriz construída a partir da análise das práticas indica a frequência e a intensidade da intersetorialidade instituída nas ações de promoção da saúde nos municípios. O Quadro 1 indica, em cada prática, como se expressa a intersetorialidade na definição política; no plano programático-normativo e nos aspectos operacionais.

$\mathrm{O}$ estudo revelou que as práticas que contam com financiamento e incentivo do Governo Federal têm como premissa a intersetorialidade. Neste contexto estão incluídas as práticas rela-

Quadro 1. Aspectos políticos, programáticos e operacionais referentes à intersetorialidade no contexto das práticas estudadas. Belo Horizonte, Minas Gerais, Brasil, 2014.

\begin{tabular}{|c|c|c|c|c|}
\hline $\begin{array}{l}\text { Características } \\
\text { das práticas }\end{array}$ & $\begin{array}{l}\text { Códigos } \\
\text { atribuídos } \\
\text { às práticas }\end{array}$ & $\begin{array}{l}\text { Nível de decisão política e } \\
\text { financiamento }\end{array}$ & $\begin{array}{c}\text { Plano } \\
\text { programático-normativo }\end{array}$ & $\begin{array}{c}\text { Aspectos } \\
\text { operacionais }\end{array}$ \\
\hline \multirow{4}{*}{$\begin{array}{l}\text { Atividade } \\
\text { Física }\end{array}$} & P3SM1 & $\begin{array}{c}\text { Política Nacional de Promoção da } \\
\text { Saúde / Financiamento Federal e } \\
\text { Municipal }\end{array}$ & $\begin{array}{l}\text { Articulação entre saúde, } \\
\text { educação e abastecimento }\end{array}$ & $\begin{array}{c}\text { Envolve profissionais } \\
\text { dos setores saúde em } \\
\text { parcerias pontuais com } \\
\text { educação }\end{array}$ \\
\hline & P8SM2 & $\begin{array}{c}\text { Política Nacional de Promoção da } \\
\text { Saúde / Financiamento Federal e } \\
\text { Municipal }\end{array}$ & $\begin{array}{c}\text { Articulação entre saúde, } \\
\text { esporte e lazer, fundação } \\
\text { municipal }\end{array}$ & $\begin{array}{c}\text { Envolve profissionais } \\
\text { dos setores saúde em } \\
\text { parcerias pontuais com } \\
\text { Esporte e lazer. }\end{array}$ \\
\hline & P24LM4 & Projeto e financiamento municipal & $\begin{array}{c}\text { Restrito ao setor Esporte } \\
\text { e lazer }\end{array}$ & $\begin{array}{l}\text { Não há evidências de } \\
\text { intersetorialidade }\end{array}$ \\
\hline & P22CM4 & Organização não governamental & $\begin{array}{l}\text { Articulação com Saúde e } \\
\text { Cultura }\end{array}$ & $\begin{array}{c}\text { Parcerias pontuais } \\
\text { (compartilhamento de } \\
\text { espaço físico) }\end{array}$ \\
\hline \multirow{3}{*}{$\begin{array}{c}\text { Práticas } \\
\text { integrativas e } \\
\text { complementares }\end{array}$} & P1SM1 & $\begin{array}{l}\text { Política Nacional de Práticas } \\
\text { Alternativas e Complementares / } \\
\text { Financiamento Federal e Municipal }\end{array}$ & Restrito ao setor saúde & $\begin{array}{l}\text { Não há evidências de } \\
\text { intersetorialidade }\end{array}$ \\
\hline & P18SM3 & $\begin{array}{c}\text { Política Nacional de Práticas } \\
\text { Alternativas e Complementares / } \\
\text { Financiamento Federal }\end{array}$ & Restrito ao setor saúde & $\begin{array}{l}\text { Não há evidências de } \\
\text { intersetorialidade }\end{array}$ \\
\hline & P20SM4 & $\begin{array}{c}\text { Política Nacional de Práticas } \\
\text { Alternativas e Complementares / } \\
\text { Financiamento Federal }\end{array}$ & Restrito ao setor saúde & $\begin{array}{l}\text { Não há evidências de } \\
\text { intersetorialidade }\end{array}$ \\
\hline $\begin{array}{c}\text { Grupos de } \\
\text { educação em saúde }\end{array}$ & P2SM1 & $\begin{array}{l}\text { Vinculado a programa Federal / } \\
\text { Financiamento Federal e Municipal }\end{array}$ & Restrito ao setor saúde & $\begin{array}{l}\text { Não há evidências de } \\
\text { intersetorialidade }\end{array}$ \\
\hline
\end{tabular}


Quadro 1. continuação

\begin{tabular}{|c|c|c|c|c|}
\hline $\begin{array}{l}\text { Características } \\
\text { das práticas }\end{array}$ & $\begin{array}{l}\text { Códigos } \\
\text { atribuídos } \\
\text { às práticas }\end{array}$ & $\begin{array}{l}\text { Nível de decisão política e } \\
\text { financiamento }\end{array}$ & $\begin{array}{c}\text { Plano } \\
\text { programático-normativo }\end{array}$ & $\begin{array}{c}\text { Aspectos } \\
\text { operacionais }\end{array}$ \\
\hline \multirow{7}{*}{$\begin{array}{c}\text { Oficinas } \\
\text { terapêuticas } \\
\text { e educativas } \\
\text { direcionadas a } \\
\text { adolescentes, idosos } \\
\text { e portadores de } \\
\text { sofrimento mental }\end{array}$} & P19SM3 & $\begin{array}{c}\text { Política Nacional de Atenção } \\
\text { Psicossocial / Financiamento Federal } \\
\text { e Municipal }\end{array}$ & $\begin{array}{l}\text { Articulação entre } \\
\text { saúde, assistência social, } \\
\text { educação e cultura }\end{array}$ & $\begin{array}{l}\text { Reuniões intersetoriais } \\
\text { quinzenais para } \\
\text { discussão e } \\
\text { planejamento }\end{array}$ \\
\hline & P5EM1 & $\begin{array}{c}\text { Política Nacional com premissa } \\
\text { intersetorial/ Financiamento Federal } \\
\text { e Municipal }\end{array}$ & $\begin{array}{l}\text { Articulação entre saúde e } \\
\text { educação }\end{array}$ & $\begin{array}{l}\text { Não há evidência de } \\
\text { intersetorialidade, } \\
\text { apesar de ser premissa } \\
\text { da política }\end{array}$ \\
\hline & P9EM2 & $\begin{array}{c}\text { Política Nacional com premissa } \\
\text { intersetorial/ Financiamento Federal } \\
\text { e Municipal }\end{array}$ & $\begin{array}{c}\text { Articulação entre } \\
\text { educação, saúde e ONG }\end{array}$ & $\begin{array}{l}\text { Parcerias restrita a } \\
\text { encaminhamentos }\end{array}$ \\
\hline & P17ASM2 & $\begin{array}{c}\text { Política Nacional do Idoso / Federal e } \\
\text { Municipal }\end{array}$ & $\begin{array}{l}\text { Articulação entre } \\
\text { assistência social, saúde e } \\
\text { empresas privadas }\end{array}$ & $\begin{array}{l}\text { Não há evidência de } \\
\text { intersetorialidade. } \\
\text { Participação pontual } \\
\text { do setor saúde }\end{array}$ \\
\hline & P25ASM4 & $\begin{array}{l}\text { Projeto municipal / Financiamento } \\
\text { municipal }\end{array}$ & $\begin{array}{l}\text { Articulação entre } \\
\text { assistência social, saúde e } \\
\text { cultura }\end{array}$ & $\begin{array}{c}\text { Parcerias restrita a } \\
\text { encaminhamentos e } \\
\text { divulgação de atividades }\end{array}$ \\
\hline & P29ASM6 & $\begin{array}{c}\text { Programa Nacional de Erradicação } \\
\text { do Trabalho Infantil / Financiamento } \\
\text { Federal e Municipal }\end{array}$ & $\begin{array}{l}\text { Articulação entre } \\
\text { assistência social, } \\
\text { educação, e saúde }\end{array}$ & $\begin{array}{l}\text { Parcerias restritas a } \\
\text { encaminhamentos }\end{array}$ \\
\hline & P23LM4 & $\begin{array}{l}\text { Projeto municipal / Financiamento } \\
\text { municipal }\end{array}$ & $\begin{array}{c}\text { Restrita ao setor Esporte } \\
\text { e Lazer }\end{array}$ & $\begin{array}{l}\text { Não há evidência de } \\
\text { intersetorialidade }\end{array}$ \\
\hline \multirow{2}{*}{$\begin{array}{l}\text { Práticas de } \\
\text { esportes com } \\
\text { escolares }\end{array}$} & P10LM2 & $\begin{array}{l}\text { Projeto Municipal / Financiamento } \\
\text { municipal }\end{array}$ & $\begin{array}{l}\text { Articulação entre esporte } \\
\text { e lazer, assistência social, } \\
\text { educação e ONG }\end{array}$ & $\begin{array}{l}\text { Parcerias pontuais } \\
\text { com educação e saúde } \\
\text { Materiais fornecidos } \\
\text { por ONG }\end{array}$ \\
\hline & P11LM2 & $\begin{array}{c}\text { Projeto Municipal / Financiamento } \\
\text { municipal }\end{array}$ & $\begin{array}{l}\text { Restrito ao setor esporte } \\
\text { e lazer }\end{array}$ & $\begin{array}{l}\text { Não há evidência de } \\
\text { intersetorialidade }\end{array}$ \\
\hline \multirow[t]{3}{*}{$\begin{array}{l}\text { Práticas de } \\
\text { integração } \\
\text { família-escola }\end{array}$} & P4EM1 & $\begin{array}{l}\text { Programa Federal de Transferência } \\
\text { de Renda / Financiamento Federal }\end{array}$ & $\begin{array}{c}\text { Articulação entre } \\
\text { assistência social, saúde e } \\
\text { educação }\end{array}$ & $\begin{array}{c}\text { Comitê municipal } \\
\text { integra os setores } \\
\text { envolvidos para } \\
\text { cumprimento de } \\
\text { condicionalidades do } \\
\text { programa }\end{array}$ \\
\hline & P27EM6 & $\begin{array}{c}\text { Programa municipal / Financiamento } \\
\text { municipal }\end{array}$ & $\begin{array}{l}\text { Articulação educação, } \\
\text { saúde e assistência social }\end{array}$ & $\begin{array}{l}\text { Parcerias pontuais } \\
\text { limitadas a } \\
\text { encaminhamentos }\end{array}$ \\
\hline & P7ASM2 & $\begin{array}{l}\text { Programa Federal de Transferência } \\
\text { de Renda / Financiamento Federal }\end{array}$ & $\begin{array}{c}\text { Articulação entre } \\
\text { assistência social, saúde e } \\
\text { educação }\end{array}$ & $\begin{array}{l}\text { Parcerias pontuais } \\
\text { limitadas a } \\
\text { encaminhamentos }\end{array}$ \\
\hline
\end{tabular}


Quadro 1. continuação

\begin{tabular}{|c|c|c|c|c|}
\hline $\begin{array}{l}\text { Características } \\
\text { das práticas }\end{array}$ & $\begin{array}{l}\text { Códigos } \\
\text { atribuídos } \\
\text { às práticas }\end{array}$ & $\begin{array}{l}\text { Nível de decisão política e } \\
\text { financiamento }\end{array}$ & $\begin{array}{c}\text { Plano } \\
\text { programático-normativo }\end{array}$ & $\begin{array}{c}\text { Aspectos } \\
\text { operacionais }\end{array}$ \\
\hline \multirow{4}{*}{$\begin{array}{c}\text { Práticas de } \\
\text { ampliação de } \\
\text { acesso, educação } \\
\text { e segurança } \\
\text { alimentar }\end{array}$} & P21EM4 & $\begin{array}{l}\text { Programas Nacionais de Segurança } \\
\text { Alimentar e Promoção da Saúde / } \\
\text { Financiamento federal e municipal }\end{array}$ & $\begin{array}{c}\text { Articulação entre } \\
\text { educação, meio ambiente, } \\
\text { saúde e assistência social }\end{array}$ & $\begin{array}{l}\text { Parcerias pontuais } \\
\text { restritas a } \\
\text { encaminhamentos }\end{array}$ \\
\hline & P6ASM1 & $\begin{array}{c}\text { Programa Nacional de Segurança } \\
\text { Alimentar / Financiamento federal e } \\
\text { municipal }\end{array}$ & $\begin{array}{l}\text { Articulação entre } \\
\text { assistência social, central } \\
\text { de abastecimento } \\
\text { alimentar, educação, } \\
\text { universidade }\end{array}$ & $\begin{array}{l}\text { Parcerias pontuais } \\
\text { restritas a } \\
\text { encaminhamentos }\end{array}$ \\
\hline & P12ASM2 & $\begin{array}{c}\text { Programa Nacional de Segurança } \\
\text { Alimentar / Financiamento federal e } \\
\text { municipal }\end{array}$ & $\begin{array}{c}\text { Articulação entre } \\
\text { assistência social, saúde e } \\
\text { central de abastecimento } \\
\text { alimentar }\end{array}$ & $\begin{array}{l}\text { Parcerias pontuais } \\
\text { restritas a } \\
\text { encaminhamentos }\end{array}$ \\
\hline & P13ASM2 & $\begin{array}{c}\text { Programa Nacional de Segurança } \\
\text { Alimentar / Financiamento federal e } \\
\text { municipal }\end{array}$ & $\begin{array}{c}\text { Articulação entre } \\
\text { assistência social, } \\
\text { Instituto de Agropecuária, } \\
\text { companhia de } \\
\text { abastecimento de água, } \\
\text { igrejas e escolas }\end{array}$ & $\begin{array}{l}\text { Trabalho multisetorial, } \\
\text { sem interlocuções } \\
\text { significativas }\end{array}$ \\
\hline $\begin{array}{l}\text { Atendimento } \\
\text { a crianças com } \\
\text { necessidades } \\
\text { especiais }\end{array}$ & P26EM5 & $\begin{array}{l}\text { Vinculado a política federal / } \\
\text { Financiamento federal e municipal }\end{array}$ & $\begin{array}{l}\text { Articulação entre } \\
\text { educação, esporte e lazer, } \\
\text { cultura }\end{array}$ & $\begin{array}{c}\text { Trabalho } \\
\text { interdisciplinar entre os } \\
\text { profissionais } \\
\text { dos setores envolvidos }\end{array}$ \\
\hline $\begin{array}{l}\text { Grupos de } \\
\text { discussão social } \\
\text { com famílias } \\
\text { beneficiadas pelo } \\
\text { programa de } \\
\text { habitação }\end{array}$ & P14ASM2 & $\begin{array}{l}\text { Plano Nacional de Habitação / } \\
\text { financiamento Federal e municipal }\end{array}$ & $\begin{array}{c}\text { Articulação entre } \\
\text { Assistência social, } \\
\text { habitação, saúde, } \\
\text { educação, defesa civil e } \\
\text { trabalho }\end{array}$ & $\begin{array}{l}\text { Participação isolada de } \\
\text { cada setor em momentos } \\
\text { diferentes da intervenção }\end{array}$ \\
\hline $\begin{array}{l}\text { Grupo de mulheres } \\
\text { que identificam } \\
\text { e intervém em } \\
\text { situações de } \\
\text { violência }\end{array}$ & P15ASM2 & $\begin{array}{l}\text { Política Nacional de Promoção } \\
\text { da Saúde - cultura de paz / } \\
\text { Financiamento Federal e municipal }\end{array}$ & $\begin{array}{c}\text { Articulação entre } \\
\text { assistência social e } \\
\text { secretaria de direitos } \\
\text { humanos }\end{array}$ & $\begin{array}{l}\text { Dados da pesquisa } \\
\text { insuficientes para } \\
\text { apontar aspectos } \\
\text { intersetoriais }\end{array}$ \\
\hline $\begin{array}{l}\text { Transporte público } \\
\text { para pessoas } \\
\text { com necessidade } \\
\text { especiais }\end{array}$ & P16ASM2 & $\begin{array}{l}\text { Projeto municipal / financiamento } \\
\text { municipal }\end{array}$ & $\begin{array}{c}\text { Articulação entre } \\
\text { assistência social, saúde, } \\
\text { educação e companhia de } \\
\text { trânsito. }\end{array}$ & $\begin{array}{l}\text { Não há evidência de } \\
\text { intersetorialidade }\end{array}$ \\
\hline $\begin{array}{l}\text { Evento } \\
\text { gastronômico e } \\
\text { cultural }\end{array}$ & P28CM6 & $\begin{array}{l}\text { Projeto municipal / financiamento } \\
\text { municipal com apoio de ONG }\end{array}$ & Restrito ao setor cultura & $\begin{array}{l}\text { Parcerias com ONG e } \\
\text { comércio local }\end{array}$ \\
\hline
\end{tabular}

Fonte: Dados da pesquisa. 
cionadas ao Programa de Segurança Alimentar (P6ASM1, P12ASM2 e P21EM4), Transferência de Renda (P4EM1 e P7ASM1), Habitação (P14ASM2), Erradicação do Trabalho Infantil (P29ASM6), Segurança Pública e Cultura de Paz (P15ASM2), além dos projetos e programas que correspondem ao eixo de atividade física da Política Nacional de Promoção da Saúde.

Essas práticas se revelaram no seu potencial intrínseco de concretização da intersetorialidade. Contudo, na maioria das vezes as premissas definidas no âmbito político se desdobram em parcerias frágeis e pontuais com desafios para de fato garantirem o compartilhamento de objetivos e responsabilidades nos aspectos operacionais. Prevaleceu, nesta dimensão, o reconhecimento da importância dos diferentes setores e profissionais, mas a expressão prevalente é a do encaminhamento e, com isso, da "desresponsabilização conjunta" por resolver os determinantes socioambientais:

Ainda não tem aquela questão assim de todo mês estar passando na escola, mas sempre que tem alguma necessidade a gente vai. Por exemplo, quando tem muita gravidez na adolescente, então vamos abordar tal tema, a gente aproveita e fala. Mas não tá aquela coisa assim, ainda bem fortalecida. Às vezes eles me pedem para dar uma palestra, mas não dá para fazer porque tem campanha de vacina e outras atividades (Gestor Saúde Município 5).

A gente buscou, tentou muito esse contato, então o centro de saúde não deu resposta, a gente já tentou varias vezes e eles falam: ah, a gente vai ver um dia que a gente pode ir aí. Só que é sempre depois do expediente, então fica difícil esse apoio (Monitor do programa P9EM2).

A matriz formada pela sistematização dos dados aponta que os projetos citados e protagonizados pelo setor assistência social destacam-se, em número, pelo planejamento normativo intersetorial. O mesmo setor também é apresentado como potencial parceiro dos programas indicados pelos setores saúde e educação. Também é expressiva a frequência de práticas planejadas para serem desenvolvidas por meio de articulação intersetorial entre saúde e educação. Emergiu dos dados que os programas dirigidos pelos setores cultura e esporte e lazer possuem um planejamento mais setorializado, quando comparado aos demais.

\section{Discussão}

Este estudo revelou que a intersetorialidade é conceituada como uma estratégia potente para enfrentar os problemas de saúde relacionados aos determinantes sociais. O reconhecimento, por parte de gestores municipais e coordenadores de práticas de promoção da saúde, sobre a necessidade da intersetorialidade para responder efetivamente à complexidade dos problemas que impactam a saúde dos sujeitos e coletivos pode ser considerado como um avanço.

Esse achado é coerente com os estudos de Carvalho et al. ${ }^{11}$, que afirma que, no Brasil, a intersetorialidade é apontada como caminho para a mudança do modelo assistencial, no entanto permanecem obstáculos referentes à operacionalização das práticas intersetoriais no cotidiano dos serviços. Andrade ${ }^{5}$ afirma que, apesar do consenso sobre as virtudes da intersetorialidade, persistem dúvidas quanto às formas de planejar, organizar, avaliar e gerir tais intervenções em colaboração.

Percebe-se um distanciamento entre os discursos dos gestores e coordenadores das práticas de promoção da saúde - que revelam a intenção de praticar a intersetorialidade, por meio de definições políticas - e a efetivação da ação intersetorial no cotidiano dos municípios. Pode-se inferir que esse achado esteja relacionado à restrição do processo de planejamento da intersetorialidade no nível macro da gestão com exclusão dos sujeitos que desenvolvem as ações. Potvin ${ }^{6}$ afirma que, apesar da ampla retórica da ação intersetorial, poucos profissionais de promoção da saúde são capazes de descrever iniciativas de sucesso.

A incoerência entre o operacional-praticado e o plano programático-normativo evidenciam que a intersetorialidade ainda constitui um desafio a ser superado. Andrade ${ }^{5}$ contribui para a análise dessa incoerência indicando que há um consenso discursivo sobre a intersetorialidade em contraposição a uma dissonância prática. Inojo$\mathrm{sa}^{9}$ afirma que a intersetorialidade para promoção da saúde, enquanto estratégia desafiadora, exige a confluência entre o ideológico e o operacional com vistas ao planejamento, implementação e avaliação de programas, projetos e práticas potentes para promover resultados sinérgicos em situações complexas.

É possível inferir que o sinergismo resultante da articulação entre saberes e práticas, proposto pelo ideário da intersetorialidade para saúde não foi alcançado pela maioria das práticas municipais analisadas. O que emergiu dos dados empí- 
ricos foi a proximidade de saberes isolados em práticas que eventualmente estabelecem alguma interação. Essa análise sustenta-se na identificação de parcerias como aquelas que acontecem entre Saúde e Educação.

Outro estudo também encontrou que apesar de haver relatos de projetos comuns - entre escolas e Unidades Básicas de Saúde-, ainda não há uma integração capaz de ultrapassar o simples fato de profissionais de saúde pública prestarem atendimentos tradicionais nas escolas locais ${ }^{6}$.

Magalhães et al. ${ }^{15}$ afirmam que a articulação entre o Programa Bolsa Família e a Estratégia Saúde da Família apresenta potencial para consolidação da ação intersetorial. Entretanto, Faria ${ }^{17}$ aponta que a ação dos agentes comunitários de saúde junto ao Programa Bolsa Família é ainda muito burocrática e a intesetorialidade entre Assistência Social, Educação e Saúde tem uma confirmação ainda incipiente.

Chama atenção a frequente atuação do setor assistência social nos programas que têm a intersetorialidade como premissa. Este achado está relacionado ao fazer próprio deste setor no enfrentamento dos determinantes socioambientais. Assim, a complexidade dos fatores sociais relacionados à segurança alimentar, habitação, saúde, segurança pública e erradicação do trabalho infantil explicita a necessidade da intersetorialidade.

Burlandy ${ }^{16}$ contribui com essa discussão apontando a intersetorialidade como estratégia para responder aos problemas relacionados à alimentação e nutrição que, por sua vez, deve envolver um conjunto de ações interligadas referentes à produção, comercialização, abastecimento, acesso e consumo dos alimentos.

No plano operacional, percebe-se ainda o estabelecimento de parcerias frágeis e pontuais, restritas a encaminhamentos, mesmo nas práticas institucionalizadas. Embora a intersetorialidade apresente avanços no plano formal de governo, no cotidiano de trabalho existem dificuldades no tocante às diferenças de valores, ideias, distribuição de recursos financeiros, humanos e políticos, tempo, disposição para reordenar processos de trabalho, dentre outros ${ }^{16}$.

A criação de grupos de trabalho intersetorial, evidenciada no estudo, pode constituir um importante dispositivo institucional de coordenação de práticas intersetoriais ao possibilitarem a construção compartilhada de projetos que dêem direção comum a diferentes setores com vistas a intervenções estratégicas. Essas iniciativas são potentes para superar as hierarquias institucionais e as relações de poder entre setores, políticas e segmentos sociais.

A constituição de espaços comunicativos permite a definição de conceitos e objetivos comuns, viabilizando, assim, o planejamento participativo de ações que demandam contribuições de diferentes setores ${ }^{17}$. De acordo com Shankardass et al. ${ }^{12}$, espaços que permitem integração e compartilhamento de informações podem se refletir em estruturas que facilitem o desenvolvimento de intervenções mais compreensivas e exitosas no que se refere à intersetorialidade para o enfrentamento de problemas relacionados às inequidades sociais.

Desenvolver a promoção da saúde sob a perspectiva intersetorial é uma tarefa complexa, que envolve grandes desafios, como a necessidade de transposição de entraves políticos e interesses pessoais, a hierarquia e a desarticulação da administração pública, que vão além da simples vontade de fazê-lo ${ }^{18}$. À medida que houver mobilização de outros campos de saber e prática profissional no sentido prático da intersetorialidade, amplia-se a capacidade de enfrentamento dos determinantes socioambientais a favor da promoção da saúde.

\section{Colaboradores}

KL Silva, RR Sena, SMM Belga, AT Rodrigues e M Akerman participaram igualmente de todas as etapas de elaboração do artigo. 


\section{Referências}

1. Loewenson R. Evaluating intersectoral processes for action on the social determinants of health: learning from key informants. Geneva: World Health Organization; [internet]. 2013. [acessado 2014 maio 22]. Disponível em: http://www.who.int/social_determinants/publications/ SDH5.pdf.

2. Koh HK, Oppenheimer SC, Massin-Short SB, Emmons KM, Geller AC, Viswanath K. Translating Research Evidence into Practice to Reduce Health Disparities: A Social Determinants Approach. Am J Public Health 2010; 100(S1):S72-S80.

3. Silva KL, Sena RR. Poder, autonomia e responsabilização: promoção da saúde em espaços sociais da vida cotidiana. Belo Horizonte: Hucitec; 2009.

4. Pedrosa JIS. Perspectivas na avaliação em promoção da saúde: uma abordagem institucional. Cien Saude Colet 2004; 9(3):617-626.

5. Andrade LO. A saúde e o dilema da intersetorialidade. São Paulo: Hucitec; 2006.

6. Potvin L. Intersectoral action for health: more research is needed! Int J Public Health 2012; 57(1):5-6.

7. Lima EC, Vilasbôas ALQ. Implantação das ações intersetoriais de mobilização social para o controle da dengue na Bahia, Brasil. Cad Saude Publica 2011; 27(8):1507-1519.

8. Wimmer GF, Figueiredo GO. Ação coletiva para qualidade de vida: autonomia, transdisciplinaridade e intersetorialidade. Cien Saude Colet 2006; 11(1):145-154.

9. Inojosa RM. Sinergia em políticas e serviços públicos: desenvolvimento social com intersetorialidade. Cad. FUNDAP 2001; 22:102-110.

10. Buss PM, Carvalho AI. Desenvolvimento da promoção da saúde no Brasil nos últimos vinte anos (1988- 2008). Cien Saude Colet 2009; 14(6):2305-2316.

11. Carvalho MF, Barbosa MI, Silva ET, Rocha DG. Intersetorialidade: diálogo da política nacional da promoção da saúde com a visão dos trabalhadores da atenção básica em Goiânia. Tempus - Actas de Saúde Coletiva. 2009; 3(3):44-55.
12. Shankardass K, Murphy K, Campos PO. A scoping review of intersectoral action for health equity involving governments. Int J Public Health 2012; 57(1):25-33.

13. Minayo MC. O desafio do conhecimento: pesquisa qualitativa em saúde. São Paulo: Hucitec; 2004.

14. Lapassade GL. L'observation participante. Revista Européia de Etnografia da Educação 2001; 1:9-26.

15. Magalhães R, Coelho AV, Nogueira MF, Bocca C. Intersetorialidade, Convergências e Sustentabilidade: Desafio do Programa Bolsa Família em Manguinhos, RJ. Cien Saude Colet 2011; 16(11):4443-4453.

16. Burlandy L. A construção da política de segurança alimentar e nutricional no Brasil: estratégias e desafios para promoção da intersetorialidade no âmbito federal de governo. Cien Saude Colet 2008; 14(3):852-860.

17. Silva KL, Rodrigues AT. Ações intersetoriais para promoção da saúde na Estratégia Saúde da Família: experiências, desafios e possibilidades. Rev Bras Enferm. 2010; 63(5):762-769.

18. Carneiro ACLL, Souza V, Godinho LK, Faria ICM, Silva KL, Gazzinelli MF. Educação para a promoção da saúde no contexto da atenção primária. Rev Panam Salud Publica 2012; 31(2):115-120.

Artigo apresentado em 16/07/2014

Aprovado em 08/08/2014

Versão final apresentada em 09/08/2014 